\title{
Molecular structure and intramolecular hydrogen bonding in 2-hydroxybenzophenones: A theoretical study
}

\author{
MANSOUREH ZAHEDI-TABRIZI ${ }^{\mathrm{a}}$, SAYYED FARAMARZ TAYYARI ${ }^{\mathrm{b}, *}$, \\ FARIDEH BADALKHANI-KHAMSEH ${ }^{\mathrm{a}}$, REIHANEH GHOMI ${ }^{\mathrm{a}}$ and \\ FATEMEH AFSHAR-QAHREMANI ${ }^{\mathrm{a}}$ \\ ${ }^{a}$ Department of Chemistry, Alzahra University, Tehran, Iran \\ ${ }^{b}$ Department of Chemistry, Shahrood Branch, Islamic Azad University, Shahrood, Iran \\ e-mail: sftayyari@gmail.com
}

MS received 1 February 2014; revised 13 March 2014; accepted 17 March 2014

\begin{abstract}
The intramolecular hydrogen bonding (IHB) in a series of 3-, 4- and 5-substituted 2hydroxybenzophenone (HBP) is studied using density functional theory calculations. All calculations are performed at the B3LYP level, using 6-311++ $\mathrm{G}^{* *}$ basis set. To understand the substitution effects on the nature of IHB and the electronic structure of the chelated ring system, the vibrational frequencies, ${ }^{1} \mathrm{H}$ chemical shift, topological parameters, natural bond orders and natural charges over atoms involved in the chelated ring of HBP and its derivatives were calculated. The Wiberg bond indices and the natural charges over atoms involved in the chelated ring have been computed using the natural bond orbital (NBO) analysis. The computations were further complemented with an atoms-in-molecules (AIM) topological analysis to characterize the nature of the IHB in the considered molecules. Several correlations between geometrical parameters, ${ }^{1} \mathrm{H}$ NMR chemical shift and topological parameters with the IHB strength are obtained.
\end{abstract}

Keywords. 2-Hydroxybenzophenone; intramolecular hydrogen bonding; DFT; NBO; AIM.

\section{Introduction}

Numerous papers have been devoted to 2-hydroxybenzoyl compounds, such as 2-hydroxybenzophenone (hereafter HBP), not only due to their simple structure but also because of their interesting and characteristic photophysical ${ }^{1,2}$ and photochemical ${ }^{3,4}$ properties. These compounds have found a wide range of applications like laser dyes, ${ }^{5,6}$ polymer stabilizers, ${ }^{7}$ Raman filters ${ }^{8}$ and hard-scintillation counters. ${ }^{9}$ HBPs are safe for topical application to humans; consequently, they are also used as sunscreens. ${ }^{10}$ These compounds are absorbed through human skin; therefore, bioaccumulation may occur in wildlife and humans. ${ }^{11,12}$ The attractive features of these compounds are their UVabsorbing power, ease of synthesis and commercial availability. HBPs, by absorbing the UV light A (315$400 \mathrm{~nm}$ ), transform into an excited state, but dissipate the absorbed energy in a harmless manner and return to the ground state; i.e., they convert the absorbed photons to heat without being chemically affected. ${ }^{13}$ A considerable amount of work has been devoted to characterize the photostabilization mechanism of these compounds. Weller's work on methyl salicylate ${ }^{1,14}$

*For correspondence suggested an extremely rapid radiationless intramolecular proton transfer of the hydroxyl proton to the carbonyl oxygen through a pre-existing intramolecular hydrogen bonding (IHB). This rapid intramolecular proton transfer is considered to be the origin of photochemical stability in a number of aromatic and heterocyclic compounds. ${ }^{15-18}$ The mechanism of proton transfer has been studied energetically using theoretical ${ }^{2,19,20}$ and experimental ${ }^{3,21}$ methods. The validity of this mechanism was questioned by Heller ${ }^{15}$ and Heller and Blattmann. ${ }^{16,17}$ Klöpffer ${ }^{18}$ concluded that proton transfer is not sufficient to explain photostability. In another investigation it was concluded that the UV stabilization process is due to the free radical scavenging. ${ }^{22}$ Allen $^{23}$ offered a mechanism for the reaction of HBPs with radicals derived from hydroperoxide photolysis and thermolysis. The radical product is no longer capable of forming the IHB. Chirinos et al. ${ }^{8}$ demonstrated that the dicumyl peroxide can be efficiently inhibited by HBP derivatives to initiate crosslinking of high-density polyethylene during the melt process. This action is almost certainly due to the alkoxyl radical scavenging. However, involving molecules in intramolecular hydrogen bonding (IHB) is the principal requirement for both mechanisms, in which HBP compounds are appropriate for this type of molecules..$^{21,23,24}$ 
Formation of IHB in these systems leads to an enhancement of resonance conjugation in the $\pi$-electron system. This kind of hydrogen bond was named by Gilli et al. $^{25}$ as resonance-assisted hydrogen bond (RAHB). The geometries and labeling of the atoms in HBP are given in figure 1 . This IHB has been the subject of many experimental and theoretical studies. Hou et al. ${ }^{26}$ examined the effects of intra- and inter-molecular hydrogen bonding on the ultrafast decay channels to the ground and triplet states. Scaiano et al. ${ }^{4}$ found that the decay of the triplet state of HBP at low temperatures takes place with a lifetime of hydrogen-bonded anti-conformer into a short-lived syn species. A theoretical study ${ }^{27}$ on the intramolecular proton transfer in HBP showed that the hydrogen-bonded structure (chelated form) is the main conformer in the ground state. The ground- and excitedstate intramolecular proton transfer reacts without a barrier between enol and keto tautomers. According to this study, the energy gap between the first excited electronic state $\left(\pi, \pi^{*}\right)$ and the second electronic state $\left(n, \pi^{*}\right)$ of the enol form is only $0.019 \mathrm{eV}$. Therefore, these excited states may occur simultaneously. Using density functional theory, natural bond orbital (NBO) analysis, atoms-in-molecules (AIM) studies, the influence of various substituents on the structure and IHB strength of HBP were investigated. The selected substituting groups were $\mathrm{NO}_{2}, \mathrm{CHO}, \mathrm{CF}_{3}, \mathrm{~F}, \mathrm{NH}_{2}, \mathrm{CN}, \mathrm{CH}_{3}$, $\mathrm{OCH}_{3}, \mathrm{OH}$ and $\mathrm{Cl}$ (all in 3-, 4-, and 5-positions). It has been shown that for the theoretical study of H-bonded systems, calculated geometrical parameters, vibrational frequencies and proton chemical shifts calculated at the B3LYP/6-311++ $\mathrm{G}^{* *}$ level of theory are in excellent agreement with the experimental results. ${ }^{28-33}$ This level of calculations was selected for all performed calculations. To get a clear understanding of the charge distributions, steric effect and hydrogen bond strength, we also performed the NBO and AIM analyses.

\section{Computational methods}

Geometry optimizations and electronic wave function calculations were performed for HBP and its derivatives in the gas phase at the B3LYP/6-311++G** level, using Gaussian 09 software package. ${ }^{34}$ The AIM computations were carried out using the AIM2000 program. ${ }^{35,36}$ To find the $\mathrm{O}-\mathrm{H}$ stretching vibrational frequencies of the stationary points in the systems under study, the harmonic frequency calculations were performed at the aforementioned level of theory. Orbital population and Wiberg bond orders ${ }^{37}$ were calculated using NBO 3.0 program implemented in Gaussian 09.

The gauge-independent atomic orbital (GIAO) method $^{38,39}$ was used for the prediction of ${ }^{1} \mathrm{H}$ NMR chemical shift of the bridged hydrogen. The predicted ${ }^{1} \mathrm{H}$ chemical shifts are derived from $\delta=\sigma_{\mathrm{o}}-\sigma$ equation, where $\delta$ is the chemical shift, $\sigma$ is the absolute shielding of bridged hydrogen and $\sigma_{\mathrm{o}}$ is the absolute shielding of hydrogen nuclei in tetramethylsilane (TMS) as the reference. The correlations between several calculated parameters with $\mathrm{IHB}$ energies, $\mathrm{E}_{\mathrm{HB}}$, have also been considered. Graphs were drawn and regression analyses were performed using Microsoft Office Excel 2010 software.

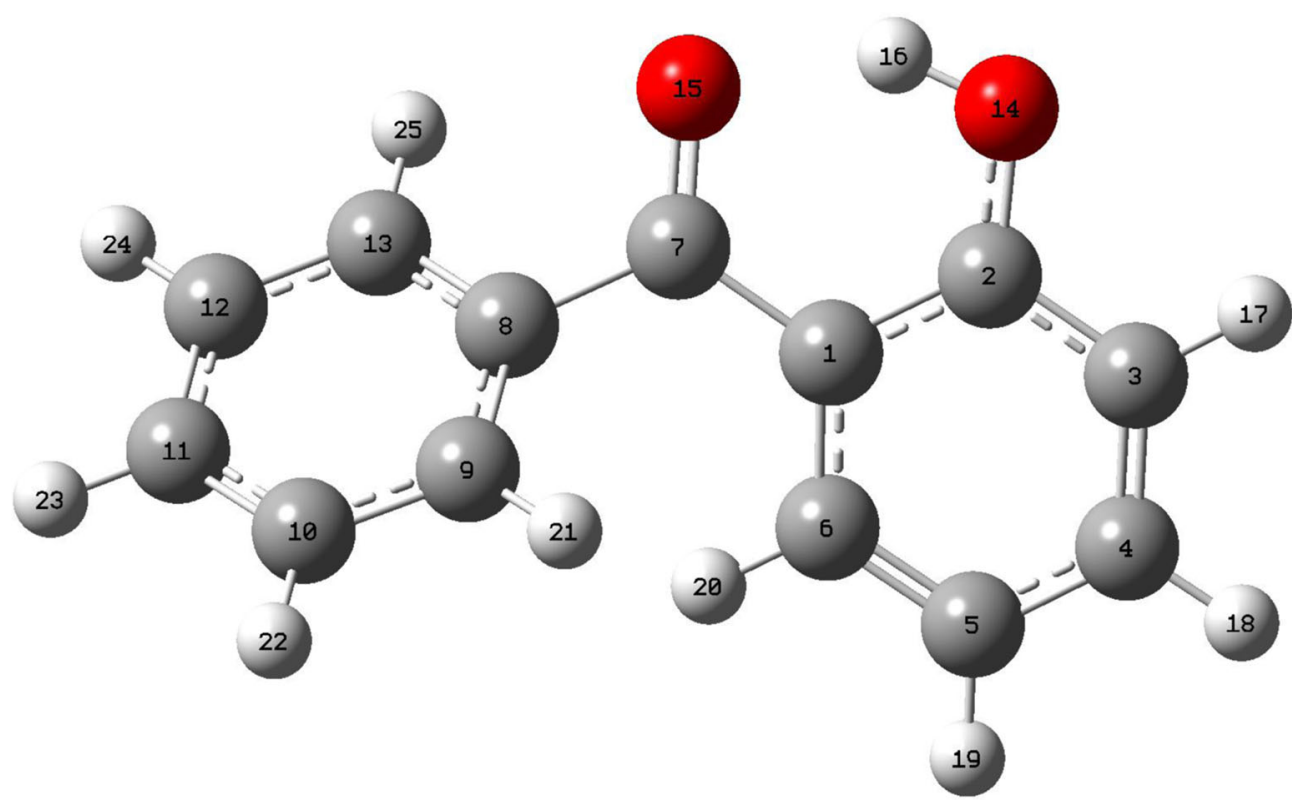

Figure 1. Structure and numbering system of HBP. 


\section{Results and Discussion}

\subsection{Aim analysis}

According to the AIM theory, upon formation of a chemical bond between two neighbouring atoms, a critical point appears between them. The nature of the chemical bond is described by the total electronic density, $\rho(r)$, and its corresponding Laplacian, $\nabla^{2} \rho(r)$ at that point. The Laplacian is the second derivative of a scalar function. Therefore, the Laplacian of electronic density gives information about the tendency of electronic density to concentrate or deplete. The Laplacian of electronic density is related to the energetic topological parameters by the following relation ${ }^{40}$

$$
\nabla^{2} \rho(r)=2 G(r)+V(r)
$$

where $G(r)$ and $V(r)$ are the kinetic and potential electronic energy densities at the critical points, respectively.
The Laplacian of a critical point is able to provide the following information:

1) A negative Laplacian indicates where the electronic density is concentrated. Lone pairs and covalent bonding are found where the Laplacian is negative.

2) A positive Laplacian shows where the electronic density is depleting. Ionic and hydrogen bonding are found where the Laplacian is positive.

In the characterization of IHBs, the bond critical point (BCP) in the hydrogen bond and the ring critical point (RCP) in the RAHB ring are valuable parameters for describing the bond. Positive values of Laplacian at the BCP show that $G(r)$ is greater than $V(r)$, which suggest depletion of the electronic charge along the bond path. This is characteristic of closed-shell interactions such as hydrogen bonds. However, negative values of Laplacian show excess potential energy at the $\mathrm{BCP}$, indicating

Table 1. Topological parameters (in a.u.), IHB energy (in kcal $/ \mathrm{mol}$ ), and the hydroxyl proton chemical shift, $\delta \mathrm{OH}$ (in ppm), for HBPs.

\begin{tabular}{|c|c|c|c|c|c|c|c|c|c|}
\hline Compound & $\rho_{\mathrm{O} \cdots \mathrm{H}}$ & $\nabla \rho_{\mathrm{O} \cdots \mathrm{H}}$ & $\mathrm{V}(\mathrm{r})_{\mathrm{O} \cdots \mathrm{H}}$ & $\mathrm{G}(\mathrm{r})_{\mathrm{O} \cdots \mathrm{H}}$ & GVR & $\rho_{\mathrm{RCP}}$ & $\nabla^{2} \rho_{\mathrm{RCP}}$ & $\mathrm{E}_{\mathrm{HB}}$ & $\delta \mathrm{OH}$ \\
\hline $3-\mathrm{NO}_{2}$ & 0.05342 & 0.1499 & -0.0538 & 0.0456 & 0.8486 & 0.02002 & 0.1231 & 16.86 & 13.57 \\
\hline 3-СHO & 0.05344 & 0.1498 & -0.0537 & 0.0456 & 0.8486 & 0.01989 & 0.1223 & 16.86 & 13.4 \\
\hline 4-MeO & 0.05302 & 0.1484 & -0.0530 & 0.0450 & 0.8500 & 0.01987 & 0.1216 & 16.63 & 13.37 \\
\hline $3-\mathrm{CF}_{3}$ & 0.05266 & 0.1493 & -0.0528 & 0.0450 & 0.8529 & 0.01985 & 0.1220 & 16.55 & 13.33 \\
\hline $4-\mathrm{NH}_{2}$ & 0.05287 & 0.1478 & -0.0527 & 0.0448 & 0.8507 & 0.01982 & 0.1213 & 16.53 & 13.12 \\
\hline 4-OH & 0.05272 & 0.1479 & -0.0526 & 0.0448 & 0.8517 & 0.0198 & 0.1213 & 16.49 & 13.19 \\
\hline 3-MeO & 0.05193 & 0.1488 & -0.0518 & 0.0445 & 0.8591 & 0.01963 & 0.1208 & 16.25 & 12.9 \\
\hline $5-\mathrm{NO}_{2}$ & 0.05186 & 0.1472 & -0.0515 & 0.0441 & 0.8572 & 0.01966 & 0.1204 & 16.16 & 13.5 \\
\hline 5-CHO & 0.05179 & 0.1474 & -0.0514 & 0.0442 & 0.8583 & 0.01963 & 0.1201 & 16.14 & 13.15 \\
\hline 3-Cl & 0.05159 & 0.148 & -0.0513 & 0.0441 & 0.8596 & 0.01975 & 0.1208 & 16.10 & 13.11 \\
\hline $3-\mathrm{CN}$ & 0.05137 & 0.1471 & -0.0509 & 0.0438 & 0.8610 & 0.01972 & 0.1205 & 15.98 & 13.25 \\
\hline 3-Me & 0.05122 & 0.1480 & -0.0508 & 0.0439 & 0.8642 & 0.0196 & 0.1196 & 15.94 & 13.04 \\
\hline 4-F & 0.05106 & 0.1464 & -0.0504 & 0.0435 & 0.8627 & 0.01957 & 0.1196 & 15.81 & 13.02 \\
\hline $3-\mathrm{NH}_{2}$ & 0.05090 & 0.1470 & -0.0504 & 0.0436 & 0.8648 & 0.01953 & 0.1191 & 15.8 & 12.91 \\
\hline $5-\mathrm{CN}$ & 0.05078 & 0.1462 & -0.0501 & 0.0433 & 0.8647 & 0.01954 & 0.1195 & 15.72 & 13.05 \\
\hline $5-\mathrm{CF}_{3}$ & 0.05048 & 0.1460 & -0.0498 & 0.0431 & 0.8669 & 0.01952 & 0.1192 & 15.70 & 13.06 \\
\hline 4-Cl & 0.05040 & 0.1456 & -0.0496 & 0.043 & 0.8669 & 0.0195 & 0.1004 & 15.56 & 12.83 \\
\hline 3-OH & 0.05031 & 0.1446 & -0.0494 & 0.0428 & 0.8664 & 0.0194 & 0.118 & 15.50 & 12.85 \\
\hline 4-Me & 0.05001 & 0.1456 & -0.0491 & 0.0427 & 0.8700 & 0.01947 & 0.1188 & 15.41 & 12.82 \\
\hline HBP & 0.04946 & 0.1452 & -0.0484 & 0.0424 & 0.8760 & 0.0194 & 0.118 & 15.19 & 12.66 \\
\hline 3-F & 0.04929 & 0.1447 & -0.0482 & 0.0422 & 0.8753 & 0.01948 & 0.118 & 15.12 & 12.57 \\
\hline $5-\mathrm{Cl}$ & 0.04921 & 0.1448 & -0.0481 & 0.0422 & 0.8762 & 0.0193 & 0.1176 & 15.09 & 12.59 \\
\hline 5-Me & 0.04903 & 0.1448 & -0.0479 & 0.0420 & 0.8768 & 0.0193 & 0.1176 & 15.03 & 12.54 \\
\hline 4-CN & 0.04900 & 0.1444 & -0.0478 & 0.0420 & 0.8773 & 0.01932 & 0.1176 & 15.01 & 12.72 \\
\hline 4-СНО & 0.04896 & 0.1445 & -0.0478 & 0.0420 & 0.8780 & 0.01933 & 0.1174 & 15.00 & 12.71 \\
\hline $4-\mathrm{CF}_{3}$ & 0.04895 & 0.1443 & -0.0478 & 0.0419 & 0.8777 & 0.01934 & 0.1176 & 14.98 & 12.79 \\
\hline $5-F$ & 0.04879 & 0.1445 & -0.0476 & 0.0419 & 0.8794 & 0.01925 & 0.117 & 14.94 & 12.45 \\
\hline 4- $\mathrm{NO}_{2}$ & 0.04849 & 0.1440 & -0.0472 & 0.0416 & 0.8814 & 0.01927 & 0.1168 & 14.81 & 12.63 \\
\hline 5-OH & 0.04786 & 0.1432 & -0.0464 & 0.0411 & 0.8858 & 0.01915 & 0.116 & 14.56 & 12.19 \\
\hline $5-\mathrm{NH}_{2}$ & 0.04737 & 0.1428 & -0.0458 & 0.0407 & 0.8899 & 0.01908 & 0.1155 & 14.36 & 11.99 \\
\hline 5-MeO & 0.04711 & 0.1424 & -0.0455 & 0.0405 & 0.8919 & 0.019 & 0.1148 & 14.28 & 12.03 \\
\hline
\end{tabular}


(a)

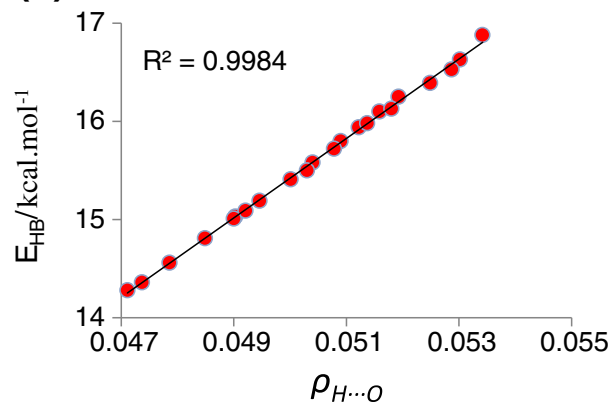

(c)



(b)

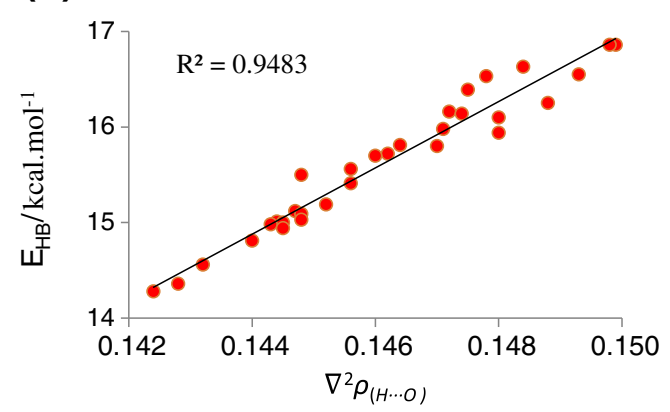

(d)

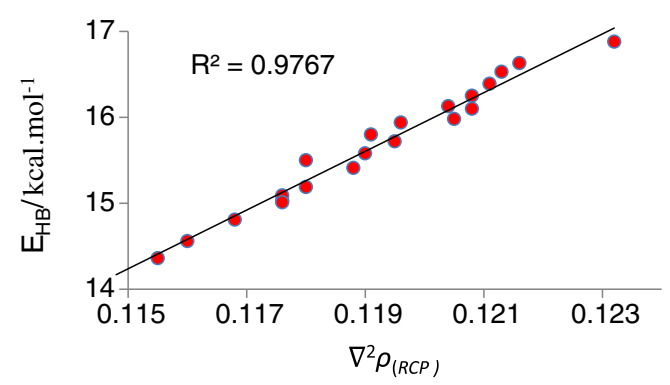

Figure 2. Linear correlations between IHB energies and, (a) Total electronic density at $\mathrm{O}$-.. H BCP, (b) Laplacian of total electronic density at BCP, (c) total electronic density at $\mathrm{RCP}$, and (d) Laplacian of total electronic density at RCP.

shared interactions such as covalent bonds. In the latter case, electronic charge is concentrated in the internuclear region and shared by both nuclei. ${ }^{41}$ According to Rozas et al. ${ }^{42}$ hydrogen bonds can be classified as follows:

- Weak hydrogen bonds $(E \mathrm{HB}<12.0 \mathrm{kcal} / \mathrm{mol})$ :

$$
\nabla^{2} \rho(r \mathrm{BCP})>0 \text { and } G(r \mathrm{BCP})+V(r \mathrm{BCP})>0
$$

- Medium hydrogen bonds $(12.0<E \mathrm{HB}<24.0 \mathrm{kcal} / \mathrm{mol})$

$$
\nabla^{2} \rho(r \mathrm{BCP})>0 \text { and } G(r \mathrm{BCP})+V(r \mathrm{BCP})<0
$$

(a)



- Strong hydrogen bonds $(E \mathrm{HB}>24.0 \mathrm{kcal} / \mathrm{mol})$ :

$$
\nabla^{2} \rho(r \mathrm{BCP})<0 \text { and } G(r \mathrm{BCP})+V(r \mathrm{BCP})<0 ;
$$

where $G(r \mathrm{BCP})+V(r \mathrm{BCP})$ is also known as total electronic energy density, $H(r \mathrm{BCP})$. According to Koch and Popelier, ${ }^{43}$ typical ranges of $\rho(r)$ and $\nabla^{2} \rho(r)$ for hydrogen bond in BCP are 0.002-0.035 $e / a_{0}^{3}$ and $0.02-$ $0.139 e / a_{0}^{5}$, respectively. However, as it is shown by Wojtulewski and Grabowski, ${ }^{44}$ in systems with $\mathrm{OH}$ donating bonds, the values of $\rho_{\mathrm{H} \cdots \mathrm{A}}$ cross the upper limit of 0.040 a.u., which corresponds to covalent bonds. As shown in table 1 , the values of $\rho_{\mathrm{O} \cdots \mathrm{H}}$ for all

(b)

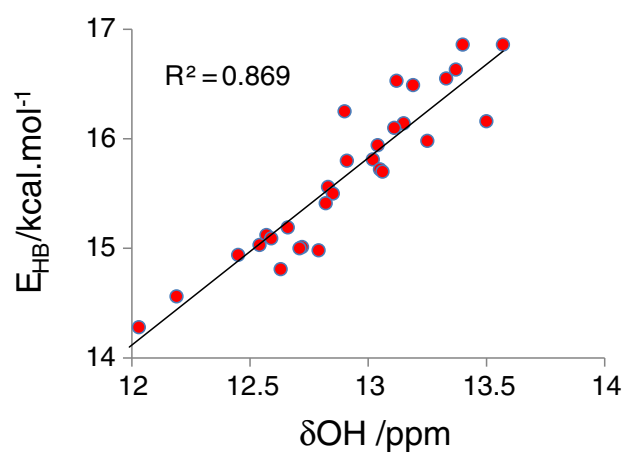

Figure 3. Linear correlations between IHB energies and (a) GVR $\left(-\mathrm{G}\left(\mathrm{R}_{\mathrm{H} \cdots \mathrm{O}}\right) / \mathrm{V}\left(\mathrm{R}_{\mathrm{H} \cdots \mathrm{O}}\right)\right.$ ratio), (b) proton chemical shift. 
systems under study are considerably more than 0.036 a.u. and lie in the $0.047-0.54$ a.u. range. The corresponding value for malonaldehyde is obtained at 0.0492 a.u. ${ }^{45}$ As shown in table 1 , the values of $\nabla^{2} \rho_{O \ldots H}, 0.142-0.150$ a.u., also cross the upper limit of 0.136 a.u. given by Koch and Popelier. ${ }^{43}$ These results confirm some covalent nature in the $I H B$.

The $-G(r \mathrm{BCP}) / V(r \mathrm{BCP})$ ratio, $G V R$, is also a descriptor for the nature of $I H B$. For $G V R>1$, the $I H B$ is non-covalent and for $0.5<G V R<1$ the $I H B$ is partly covalent. ${ }^{46}$ As shown in table 1 , the GVRs are considerably lower than unity, 0.849-0.892, which also confirms that the $I H B$ in these systems is partly covalent. The prediction of hydrogen bond energy of $I H B S$ is an important subject. A reliable method for estimation of
$I H B$ energy, which is suggested by Espinosa et al. $^{47}$ is using the potential electronic energy density at the critical point by the expression $E H B=1 / 2 V(r \mathrm{BCP})$. The calculated total electronic density and its corresponding Laplacian at the bond critical point and ring critical point, potential electronic energy density, kinetic electronic energy density, GVR at the bond critical point, and IHB energy, $E_{\mathrm{HB}}$, along with the NMR chemical shift of the hydroxyl proton, $\delta \mathrm{OH}$, are collected in table 1 .

According to table 1, for all molecules under investigation, Laplacian of total electronic densities at the BCPs are positive and reveal that the electronic charges are depleted in the interatomic path, which is characteristic of closed-shell interactions. Table 1 also shows

Table 2. The most important geometrical parameters, Gilli's coordinates (in $\AA$ ), and hydrogen bond energies, $E_{\mathrm{HB}}$ (in $\mathrm{kcal} / \mathrm{mol}$ ), for $2 \mathrm{HBP}$ and its derivatives. ${ }^{\mathrm{a}}$

\begin{tabular}{|c|c|c|c|c|c|c|c|c|c|c|c|}
\hline Compound & & $\mathrm{dC}-\mathrm{C}$ & $\mathrm{dC}=\mathrm{C}$ & $\mathrm{dC}=\mathrm{O}$ & $\mathrm{dC}-\mathrm{O}$ & $\mathrm{dH} \cdots \mathrm{O}$ & $\mathrm{RO} \cdots \mathrm{O}$ & $\mathrm{dO}-\mathrm{H}$ & $\mathrm{q} 1$ & $\mathrm{q} 2$ & Q \\
\hline \multirow[t]{2}{*}{ 2HBP } & Cal. & 1.4737 & 1.4237 & 1.2394 & 1.3400 & 1.6883 & 2.5702 & 0.9872 & 0.0500 & 0.1006 & 0.1506 \\
\hline & Exp. ${ }^{b}$ & $1.463(4)$ & $1.405(4)$ & $1.240(4)$ & $1.350(4)$ & $1.81(4)$ & $2.561(4)$ & $0.84(4)$ & & & \\
\hline $3-\mathrm{NO}_{2}$ & Cal. & 1.4796 & 1.4292 & 1.2378 & 1.3243 & 1.6502 & 2.5449 & 0.9918 & 0.0504 & 0.0865 & 0.1369 \\
\hline $4-\mathrm{NO}_{2}$ & Cal. & 1.4824 & 1.4229 & 1.2365 & 1.3363 & 1.6956 & 2.5723 & 0.9868 & 0.0595 & 0.0998 & 0.1593 \\
\hline $5-\mathrm{NO}_{2}$ & Cal. & 1.4809 & 1.4274 & 1.2379 & 1.3303 & 1.6693 & 2.5565 & 0.9909 & 0.0535 & 0.0924 & 0.1459 \\
\hline $3-\mathrm{CH}_{3}$ & Cal. & 1.4729 & 1.4220 & 1.2402 & 1.3423 & 1.6734 & 2.5606 & 0.9884 & 0.0509 & 0.1021 & 0.153 \\
\hline 4- $\mathrm{CH}_{3}$ & Cal. & 1.4696 & 1.4222 & 1.2408 & 1.3398 & 1.6839 & 2.5686 & 0.9881 & 0.0474 & 0.099 & 0.1464 \\
\hline $5-\mathrm{CH}_{3}$ & Cal. & 1.4727 & 1.4203 & 1.2398 & 1.3413 & 1.6920 & 2.5723 & 0.9868 & 0.0524 & 0.1015 & 0.1539 \\
\hline 3-MeO & Cal. & 1.4746 & & & & & & & 27 & 09 & 0.1536 \\
\hline \multirow[t]{2}{*}{ 4-МeO } & Cal. & 1.4633 & 1.4239 & 1.2434 & 1.3381 & 1.6609 & 2.5 & 0.9915 & 0.0394 & 0.0947 & 0.1341 \\
\hline & Exp. $^{\mathrm{c}}$ & 1.447 & 1.405 & 1.255 & 1.355 & 1.53 & 2.55 & 1.04 & & & \\
\hline 5-MeO & Cal. & 1.4768 & 1.4226 & 1.2381 & 1.3 & & & 843 & 42 & 0 . & 0.1621 \\
\hline 3-OH & Cal. & 1.4747 & 1.4129 & 1.2403 & 1.3499 & 1.6813 & 2.5584 & 0.9898 & 0.0618 & 0.1096 & 0.1714 \\
\hline \multirow[t]{2}{*}{ 4-ОН } & Cal. & 1.4648 & 1.4263 & 1.2429 & 1.3374 & & & 0.9913 & 0.0385 & 0.0945 & 0.133 \\
\hline & Exp. $^{\mathrm{d}}$ & $1.453(5)$ & $1.409(5)$ & $1.253(4)$ & $1.361(4)$ & 1.51 & $2.550(4)$ & 1.1 & & & \\
\hline $\mathbf{H}$ & Cal. & 1.4732 & 1.4186 & 1.2389 & 1.3437 & & 2.5778 & 0.9854 & 46 & & 594 \\
\hline 3-Cl & Cal. & 1.4772 & 1.4245 & 1.23 & 1.3 & 1. & 2. & 92 & 27 & 0. & 0.1467 \\
\hline & Cal. & & & & & & & & & & \\
\hline \multirow[t]{2}{*}{ 5-Cl } & Cal. & 1.4772 & 1.4219 & 1.2383 & 1.3389 & 1.6 & 2.5701 & 0.9870 & 0.0553 & 0.1006 & 0.1559 \\
\hline & Exp. $^{\mathrm{e}}$ & $1.472(2)$ & $1.415(2)$ & $1.2392(2)$ & $1.351(2)$ & $1.73(2)$ & $2.571(1)$ & $0.92(2)$ & & & \\
\hline $3-\mathrm{NH}_{2}$ & Cal. & 1.4737 & 1.4138 & 1.2405 & 1.3485 & 1.6 & 2.5 & 386 & 99 & 0.1 & 0.1679 \\
\hline $4-\mathrm{NH}_{2}$ & Cal. & 1.4593 & 1.4293 & 1.2448 & 1.3389 & 1.6623 & 2.5579 & 0.9913 & 0.0300 & 0.0941 & 0.1241 \\
\hline $5-\mathrm{NH}_{2}$ & Cal. & & & & & & & & & & 0.1625 \\
\hline $3-\mathrm{CN}$ & Cal. & 1.4793 & 1.4234 & 1.23 & 1.3292 & 1.6 & & 0.9900 & 59 & 0.0 & 0.1475 \\
\hline $4-\mathrm{CN}$ & Cal. & 1.4800 & 1.4227 & & & & & & 0.0366 & 0.0996 & 0.1362 \\
\hline 5-CN & Cal. & 1.4803 & 1.4250 & 1.2378 & 1.3329 & 1.6772 & 2.5613 & 895 & 0.0553 & 0.0951 & 0.1504 \\
\hline 3-СHO & Cal. & 1.4762 & 1.4266 & 1.2394 & 1.3356 & 1.6558 & 2.5485 & 0.9911 & 0.0496 & 0.0962 & 0.1458 \\
\hline 4-СНO & Cal. & 1.4792 & 1.4215 & 1.2380 & 1.3387 & 1.6920 & 2.5703 & 0.9871 & 0.0577 & 0.1007 & 0.1584 \\
\hline 5-СНO & Cal. & 1.4803 & 1.4300 & 1.2386 & 1.3327 & 1.6693 & 2.5571 & 0.9903 & 0.0503 & 0.0941 & 0.1444 \\
\hline $3-\mathrm{CF}_{3}$ & Cal. & 1.4774 & 1.4244 & 1.2385 & 1.3311 & & 2.5505 & 0.9903 & 0.0503 & 0.0941 & 0.1444 \\
\hline $4-\mathrm{CF}_{3}$ & Cal. & 1.4729 & 1.4240 & 1.2395 & 1.3370 & 1.6822 & 2.5668 & 0.9888 & 0.0503 & 0.0941 & 0.1444 \\
\hline $5-\mathrm{CF}_{3}$ & Cal. & 1.4783 & 1.4237 & 1.2382 & 1.3344 & 1.6797 & 2.5634 & 0.9890 & 0.0503 & 0.0941 & 0.1444 \\
\hline 3-F & Cal. & 1.4771 & 1.4214 & 1.2383 & 1.3348 & 1.6894 & 2.5692 & 0.9876 & 0.0557 & 0.0965 & 0.1522 \\
\hline 4-F & Cal. & 1.4714 & 1.4265 & 1.2400 & 1.3363 & 1.6755 & 2.5627 & 0.9895 & 0.0449 & 0.0963 & 0.1412 \\
\hline $5-F$ & Cal. & 1.4766 & 1.4219 & 1.2381 & 1.3411 & 1.6936 & 2.5723 & 0.9864 & 0.0547 & 0.103 & 0.1577 \\
\hline
\end{tabular}

a) Cal., calculated; Exp. Experimental. b) Data from Ref. ${ }^{49}$ c) Data from Ref. ${ }^{50}$ d) Data from Ref. ${ }^{51}$ e) Data from Ref. ${ }^{52}$ $\mathrm{q} 1=\left(\mathrm{d}_{\mathrm{C}-\mathrm{C}}-\mathrm{d}_{\mathrm{C}=\mathrm{C}}\right) ; \mathrm{q} 2=\left(\mathrm{d}_{\mathrm{C}-\mathrm{O}}-\mathrm{d}_{\mathrm{C}=\mathrm{O}}\right) ; \mathrm{Q}=\mathrm{q} 1+\mathrm{q} 2$ 
that the $-G(r) / V(r)$ values, GVR, in all cases are considerably less than unity, which indicates that the hydrogen bonds in these systems are partially covalent. It has been shown that for those hydrogen bonds for which their strength is greater than $8 \mathrm{kcal} / \mathrm{mol}, G V R s$ are less than unity. ${ }^{45}$

The calculated hydrogen bond energies, according to the Espinosa's equation, ${ }^{47}$ along with the proton chemical shifts of bridge proton are listed in the last column of table 1. According to this table and considering the Rozas classification, ${ }^{42}$ all $I H B$ s investigated in this study are classified as medium strength.

Excellent correlations between electronic density at the bond critical points, its corresponding Laplacian, electronic density at the ring critical points and its corresponding Laplacian with the hydrogen bond strength, $E_{\mathrm{HB}}$, were obtained, which are shown in figures $2 \mathrm{a}$, $2 \mathrm{~b}, 2 \mathrm{c}$ and $2 \mathrm{~d}$, respectively. An excellent correlation between $G V R$ and $E_{\mathrm{HB}}$ is also obtained, which is depicted in figure $3 \mathrm{a}$. The linear regression equation obtained for this correlation is as follows:

$$
E_{\mathrm{HB}}=-58.433(G V R)+66.307
$$

with a regression coefficient, $\mathrm{R}^{2}=0.9880$ and standard deviation, $\mathrm{SD}=0.08 \mathrm{kcal} / \mathrm{mol}$. According to eq. (2) the $G V R=1$ corresponds to a hydrogen bond energy of $7.87 \pm 0.08 \mathrm{kcal} / \mathrm{mol}$, which is in excellent agreement with the corresponding value reported for a bent $\mathrm{N}-\mathrm{H} \cdots \mathrm{N}$ system, $8 \mathrm{kcal} / \mathrm{mol}^{45}$

(a)

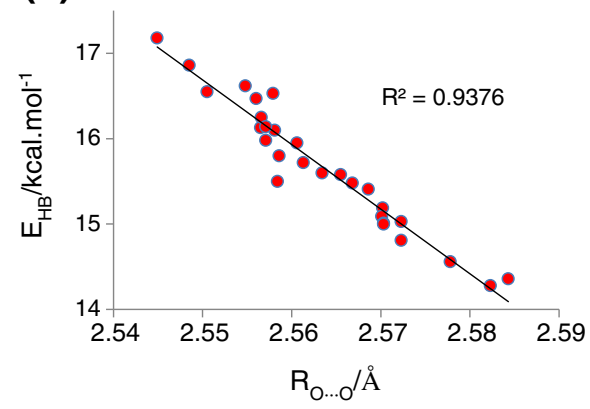

(c)



A fairly good correlation $\left(\mathrm{R}^{2}=0.869\right)$ is also obtained between the hydroxyl proton chemical shift and $\mathrm{E}_{\mathrm{HB}}$, as demonstrated in figure $3 \mathrm{~b}$.

As it is shown in table 1 , the hydrogen bond energies, $E_{\mathrm{HB}}$, of 5-substituted electron releasing and 4substituted electron withdrawing derivatives are lower than that of parent molecule, $H B P$. These results will be explained in section 3.3.

Electron-withdrawing groups in 4-position (para with respect to $\mathrm{C} 1$ ) reduce the electronic charge over $\mathrm{C} 1$, which, in turn, reduces the charge over $\mathrm{O} 5$ atom. Reducing the electronic charge over O5 (proton acceptor group) reduces the hydrogen bond strength. On the other hand, substitution of electron-releasing groups in the 5-position (para with respect to $\mathrm{C} 2$ ) increases the charge over $\mathrm{C} 2$, which, in turn, increases the electronic charge over $\mathrm{O} 1$ atom. Increasing the electronic charge over $\mathrm{O} 1$ atom (proto donating group) also reduces the hydrogen bond strength.

\subsection{Molecular geometry}

The most important geometrical parameters for $H B P$ and its $\mathrm{NO}_{2}, \mathrm{CHO}, \mathrm{O}-\mathrm{CH}_{3}, \mathrm{CH}_{3}, \mathrm{CF}_{3}, \mathrm{OH}, \mathrm{NH}_{2}$, $\mathrm{CN}, \mathrm{F}$ and $\mathrm{Cl}$ derivatives at the 3-, 4- and 5- positions (31 molecules) along with the Gilli's symmetry coordinates $\left(q_{1}=\left(d_{\mathrm{C}-\mathrm{C}}-d_{\mathrm{C}=\mathrm{C}}\right), q_{2=}\left(d_{\mathrm{C}-\mathrm{O}}-d_{\mathrm{C}=\mathrm{O}}\right)\right.$, and $\left.Q=q_{1}+q_{2}\right)^{48}$ are listed in table 2. For comparison, the $\mathrm{x}$-ray crystallographic experimental data (b)



(d)

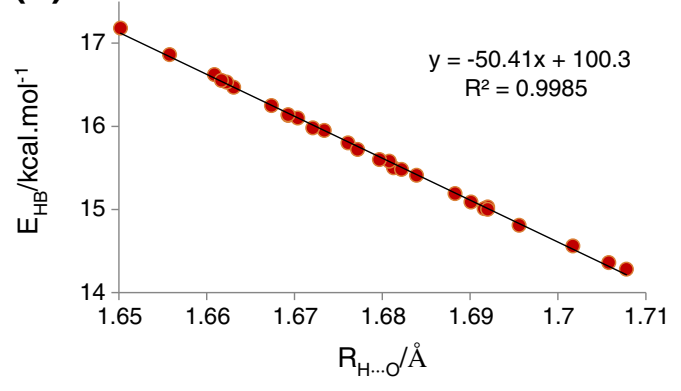

Figure 4. Linear correlations between IHB energies and (a) $\mathrm{R}_{\mathrm{O} \cdots \mathrm{O}}$, (b) $\mathrm{R}_{\mathrm{O}-\mathrm{H} \cdots \mathrm{O}}\left(\mathrm{R}_{\mathrm{O}-\mathrm{H}}+\mathrm{R}_{\mathrm{H} \cdots \mathrm{O}}\right)$, (c) $\mathrm{R}_{\mathrm{O}-\mathrm{H}}$, and (d) $\mathrm{R}_{\mathrm{H} \cdots \mathrm{O}}$. 
of $H B P,{ }^{49}$ 3-methoxy-HBP (3-MeO), ${ }^{50}$ 4-hydroxy-HBP $(4-\mathrm{OH})^{51}$ and 5-choloro-HBP $(5-\mathrm{Cl})^{52}$ are also given in table 2. According to table 2, there is satisfactory agreement between experimental data and theoretical calculations.

In this section, the effect of substitutions on the structural parameters $(\mathrm{C}-\mathrm{O}(\mathrm{d} 1), \mathrm{C}=\mathrm{C}(\mathrm{d} 2), \mathrm{C}-\mathrm{C}(\mathrm{d} 3)$, $\mathrm{C}=\mathrm{O}(\mathrm{d} 4)$, and $\mathrm{O}-\mathrm{H}\left(\mathrm{R}_{\mathrm{O}-\mathrm{H}}\right)$ bond lengths, and $\mathrm{O} \cdots \mathrm{O}$ $\left(\mathrm{R}_{\mathrm{O} \cdots \mathrm{O}}\right), \mathrm{O} \cdots \mathrm{H}\left(\mathrm{R}_{\mathrm{O} \cdots \mathrm{H}}\right)$, and $\mathrm{O}-\mathrm{H}+\mathrm{H} \cdots \mathrm{O}\left(\mathrm{R}_{\mathrm{O}-\mathrm{H} \cdots \mathrm{O}}\right)$ distances) have been discussed. Table 2 shows that the effect of substitution is highly dependent on the substitution position. The hydrogen bond distance, $\mathrm{R}_{\mathrm{O} \ldots \mathrm{O}}$, in the 3-substituted derivatives, regardless of whether the substituted group is electron withdrawing or electron releasing, is considerably reduced compared to the parent molecule, HBP. However, the electron-releasing and -withdrawing groups substituted at the 3-position have different effects on the $\mathrm{C}-\mathrm{C}, \mathrm{C}=\mathrm{C}, \mathrm{C}-\mathrm{O}$ and $\mathrm{C}=\mathrm{O}$ bond lengths. Therefore, it is concluded that decreasing of $\mathrm{R}_{\mathrm{O} \ldots \mathrm{O}}$ by 3 -substituted groups is mainly caused by steric effects. The unusual behaviour of $F$ atom could be explained by its small size (least steric effect) and its electronreleasing nature in the ortho position with respect to $\mathrm{C} 2$. The correlations between $\mathrm{O} \cdots \mathrm{O}$ distance and $E_{\mathrm{HB}}$ is shown in figure $4 \mathrm{a}$. The linear correlation coefficient, $\mathrm{R}^{2}$, for this analysis is 0.9376 . However, as shown in figure $4 \mathrm{~b}$, an excellent correlation was obtained between the hydrogen bond strength and the $\mathrm{R}_{\mathrm{O}-\mathrm{H} \cdots \mathrm{O}}\left(\mathrm{R}_{\mathrm{O}-\mathrm{H}}+\mathrm{R}_{\mathrm{H} \cdots \mathrm{O})}\right.$ with a linear correlation coefficient very close to $1.000, \mathrm{R}^{2}=0.9984$. This result suggests that for the bent hydrogen bonded systems, the $\mathrm{O} \cdots \mathrm{O}$ distance is not a very good parameter for the estimation of hydrogen bond strength and it is better to be replaced by $\mathrm{R}_{\mathrm{O}-\mathrm{H} \ldots \mathrm{O}}$. Similar result has been also reported for the bent $\mathrm{N}-\mathrm{H} \cdots \mathrm{N}$ systems. ${ }^{45}$ Figures $4 \mathrm{c}$ and $4 d$ indicate the plots of $E_{\mathrm{HB}}$ versus $\mathrm{R}_{\mathrm{O}-\mathrm{H}}$ and $\mathrm{R}_{\mathrm{H} \cdots \mathrm{O}}$. These figures also show that $R_{\mathrm{H} \ldots \mathrm{O}}$ is an excellent parameter to describe the hydrogen bond strength. The correlation of Gilli's symmetry coordinate, $Q$, with the hydrogen bond strength, is given in figure 5a. Here the data of 3-substituted derivatives are far away from the correlation line. To obtain a better correlation between $Q$ and $E_{\mathrm{HB}}$, the data due to the 3-substituted derivatives are excluded from regression analysis $\left(\mathrm{R}^{2}=0.8814\right)$. Figure 5a indicates, as it has also been shown for the $\mathrm{N}-\mathrm{H} \cdots \mathrm{N}$ system, ${ }^{45}$ that the Gilli's symmetry coordinate, ${ }^{48} Q$, is not a good parameter for description of $I H B$ strength, at least in systems with high degree of steric hindrance.

It is noteworthy that there is no significant correlation between $\mathrm{d} 1, \mathrm{~d} 2, \mathrm{~d} 3$ and $\mathrm{d} 4$ parameters with the $I H B$ strength.


Figure 5. Linear correlation between IHB and (a) Gilli's coordinate, Q, for 4- and 5-substitutions, $\bullet$. The 3 -substituted derivatives, $\diamond$, are excluded, (b) sum of natural charges over all chelated ring atoms of 3-sub.,, 4 -sub., $\boldsymbol{\Delta}$, and 5-sub., $\bullet$, subtracted from the corresponding value for HBP, and (d) the natural charge difference over $\mathrm{O} 14$ and $\mathrm{O} 15$ subtracted from the corresponding value for HBP.

\subsection{NBO analysis}

To understand the charge redistribution in the enol ring induced by the substituted groups, the natural charges over all atoms involved in the chelated ring are calculated and listed in table 3 . However, there is no significant linear correlation between natural charges over single atom and $E_{\mathrm{HB}}$, but fairly good correlations were obtained by regression analyses of correlations between sum of the natural charges, $\Sigma q_{i}$, over all atoms engaged in the chelated ring with $E_{\mathrm{HB}}$ for each 3-, 4- and 5substituted derivatives. The correlation between $\Sigma q_{i}-$ $\Sigma q_{i}^{\mathrm{o}}$, where $-\Sigma q_{i}^{\mathrm{o}}$ is the corresponding value for HBP, as shown in figure $5 \mathrm{~b}$. Here the best correlation is obtained for 5-substituted derivatives $\left(\mathrm{R}^{2}=0.9298\right)$, without 
Table 3. Natural charge (e) distribution on the chelated ring atoms (qi) and selected Wiberg bond orders.

\begin{tabular}{|c|c|c|c|c|c|c|c|c|c|}
\hline Comp. & qo14 & qo15 & $\mathrm{q}_{\mathrm{C} 1}$ & $\mathrm{q}_{\mathrm{C} 2}$ & $\mathrm{q}_{\mathrm{C} 7}$ & $\mathrm{q}_{\mathrm{H} 16}$ & $\mathrm{~B}_{\mathrm{O}-\mathrm{H}}$ & $\mathrm{B}_{\mathrm{O} \cdots \mathrm{H}}$ & $\mathrm{B}_{\mathrm{O} \cdots \mathrm{O}}$ \\
\hline 5-MeO & -0.6763 & -0.6093 & -0.2037 & 0.3586 & 0.5498 & 0.5019 & 0.6632 & 0.0708 & 0.0359 \\
\hline $5-\mathrm{NH}_{2}$ & -0.6767 & -0.6125 & -0.2046 & 0.3593 & 0.5462 & 0.5019 & 0.6544 & 0.0761 & 0.0360 \\
\hline 5-OH & -0.6727 & -0.6100 & -0.2066 & 0.3661 & 0.5452 & 0.5025 & 0.6604 & 0.0729 & 0.0384 \\
\hline $4-\mathrm{NO}_{2}$ & -0.6576 & -0.5981 & -0.1979 & 0.3866 & 0.5517 & 0.5049 & 0.6549 & 0.0742 & 0.0349 \\
\hline 4-CN & -0.6597 & -0.6009 & -0.2045 & 0.3853 & 0.5503 & 0.5047 & 0.6544 & 0.0761 & 0.0366 \\
\hline $5-\mathrm{CH}_{3}$ & -0.6707 & -0.6137 & -0.2198 & 0.3826 & 0.5478 & 0.5026 & 0.6567 & 0.0761 & 0.0382 \\
\hline 5-Cl & -0.6659 & -0.6069 & -0.2078 & 0.3829 & 0.5503 & 0.5035 & 0.6554 & 0.0765 & 0.0375 \\
\hline 3-F & -0.6524 & -0.6075 & -0.2127 & 0.3295 & 0.5509 & 0.5043 & 0.6542 & 0.0770 & 0.0371 \\
\hline HBP & -0.6659 & -0.6119 & -0.2289 & 0.3878 & 0.5490 & 0.5029 & 0.6554 & 0.0770 & 0.0372 \\
\hline $4-\mathrm{CH}_{3}$ & -0.6688 & -0.6163 & -0.2373 & 0.3983 & 0.5463 & 0.5030 & 0.6533 & 0.0791 & 0.0382 \\
\hline 4-СHO & -0.6645 & -0.6038 & -0.202 & 0.3805 & 0.5497 & 0.5044 & 0.6555 & 0.0759 & 0.0374 \\
\hline $4-\mathrm{CF}_{3}$ & -0.6609 & -0.6034 & -0.2107 & 0.3897 & 0.5513 & 0.5044 & 0.6511 & 0.0799 & 0.0378 \\
\hline 3-OH & -0.7054 & -0.6149 & -0.2489 & 0.3222 & 0.5420 & 0.5038 & 0.6415 & 0.0814 & 0.0364 \\
\hline 4-Cl & -0.6633 & -0.6105 & -0.2277 & 0.4011 & 0.5479 & 0.5041 & 0.6508 & 0.0803 & 0.0379 \\
\hline $5-\mathrm{CF}_{3}$ & -0.6588 & -0.6055 & -0.2182 & 0.4000 & 0.5531 & 0.5044 & 0.6505 & 0.0801 & 0.0347 \\
\hline $5-\mathrm{CN}$ & -0.6551 & -0.6033 & -0.2184 & 0.4032 & 0.5541 & 0.5050 & 0.6490 & 0.0809 & 0.0370 \\
\hline $3-\mathrm{NH}_{2}$ & -0.6948 & -0.6164 & -0.2134 & 0.3506 & 0.5524 & 0.5073 & 0.6475 & 0.0809 & 0.0380 \\
\hline 4-F & -0.6637 & -0.6126 & -0.2368 & 0.4015 & 0.5475 & 0.5040 & 0.6491 & 0.0820 & 0.0380 \\
\hline $3-\mathrm{CH}_{3}$ & -0.6744 & -0.6144 & -0.2220 & 0.3889 & 0.5494 & 0.5032 & 0.6510 & 0.0811 & 0.0387 \\
\hline $3-\mathrm{CN}$ & -0.6463 & -0.6013 & -0.2220 & 0.4307 & 0.5543 & 0.5071 & 0.6453 & 0.0822 & 0.0370 \\
\hline 3-Cl & -0.6528 & -0.6069 & -0.2115 & 0.3618 & 0.5518 & 0.5038 & 0.6488 & 0.0822 & 0.0383 \\
\hline $5-\mathrm{NO}_{2}$ & -0.6502 & -0.6031 & -0.2143 & 0.4103 & 0.5549 & 0.5054 & 0.6454 & 0.0839 & 0.0371 \\
\hline 5-CHO & -0.6553 & -0.6066 & -0.2216 & 0.4092 & 0.5557 & 0.5047 & 0.6469 & 0.0832 & 0.0361 \\
\hline 3-МeO & -0.6744 & -0.6131 & -0.2186 & 0.3491 & 0.5511 & 0.5041 & 0.6481 & 0.0830 & 0.0389 \\
\hline 4-OH & -0.6701 & -0.6221 & -0.2489 & 0.4068 & 0.5419 & 0.5038 & 0.6448 & 0.0867 & 0.0392 \\
\hline $4-\mathrm{NH}_{2}$ & -0.6732 & -0.6293 & -0.2565 & 0.4083 & 0.535 & 0.5027 & 0.6452 & 0.0875 & 0.0387 \\
\hline $3-\mathrm{CF}_{3}$ & -0.6531 & -0.6041 & -0.2195 & 0.4164 & 0.5526 & 0.5059 & 0.6435 & 0.0832 & 0.0361 \\
\hline 4-MeO & -0.6708 & -0.6243 & -0.2554 & 0.4109 & 0.5412 & 0.5037 & 0.6442 & 0.0873 & 0.0394 \\
\hline 3-CHO & -0.6673 & -0.6076 & -0.2267 & 0.4234 & 0.5523 & 0.5058 & 0.6414 & 0.0873 & 0.0387 \\
\hline $3-\mathrm{NO}_{2}$ & -0.6343 & -0.5997 & -0.2141 & 0.396 & 0.5534 & 0.5052 & 0.6417 & 0.0867 & 0.0372 \\
\hline $5-F$ & -0.6691 & -0.6068 & -0.2062 & 0.3731 & 0.5485 & 0.5032 & 0.6571 & 0.0753 & 0.0379 \\
\hline
\end{tabular}

a) q, natural charge; B, Wiberg bond order.

steric effect, and the worst correlation $\left(\mathrm{R}^{2}=0.4125\right)$ is obtained for the 3-substituted derivatives, which have the highest steric hindrance. According to figure 5b, the electron-withdrawing and -releasing substituted groups have different effects at the 4- and 5-positions. These behaviours could be explained as follows:

The electron-withdrawing groups in 4-position (para with respect to $\mathrm{C} 1$ ) reduce the charge over $\mathrm{C} 1$, which, in turn, reduces the charge over $\mathrm{O} 15$ atom. Reducing the electron charge over O5 (proton acceptor group) reduces the IHB strength. On the other hand, substitution of the electron-releasing groups in the 5-position (para with respect to $\mathrm{C} 2$ ) increases the charge over $\mathrm{C} 2$, which, in turn, increases the electronic charge over $\mathrm{O} 14$ atom. Increasing the electronic charge over O14 atom (proton donating group) also reduces the IHB strength.

Another parameter, which could be considered for estimation of $I H B$ strength, is the natural charge difference between $\mathrm{O} 14$ and $\mathrm{O} 15, \Delta \mathrm{q}_{\mathrm{O} \ldots \mathrm{O}}$. The relationship between $\Delta \mathrm{q}_{\mathrm{O} \ldots \mathrm{O}}$ and $E_{\mathrm{HB}}$ is shown in figure $5 \mathrm{c}$. As it is obvious from figure $5 \mathrm{c}$, the behaviour of this parameter for the 3-substituted derivatives is not in the same line with other derivatives. This result also indicates that the effect of the 3 -substituted groups is mainly steric hindrance, not charge redistribution. In the regression analysis of $\Delta \mathrm{q}_{\mathrm{O} \ldots \mathrm{O}}$ with $E_{\mathrm{HB}}$, given in figure $5 \mathrm{c}$, the data due to the 3 -substituted derivatives are excluded.

To allow for a more quantitative comparison between the bonding in $H B P$ and its derivatives, the Wiberg bond indices $^{37}$ for $\mathrm{O} \cdots \mathrm{H}$ and $\mathrm{O}-\mathrm{H}$ were also calculated and given in table 3 . The main effect of 3-substitution of an electron-releasing or electron-withdrawing group is the increasing of $\mathrm{H} \cdots \mathrm{O}$ and decreasing of $\mathrm{O}-\mathrm{H}$ bond orders in comparison with the matching values for $H B P$. Excellent correlations were also obtained between $E_{\mathrm{HB}}$ with $\mathrm{O}-\mathrm{H}\left(\mathrm{R}^{2}=0.9364\right)$ and $\mathrm{H} \cdots \mathrm{O}\left(\mathrm{R}^{2}=0.9790\right)$ bond orders, which are shown in figures $6 a$ and $6 \mathrm{~b}$, respectively. 
(a)

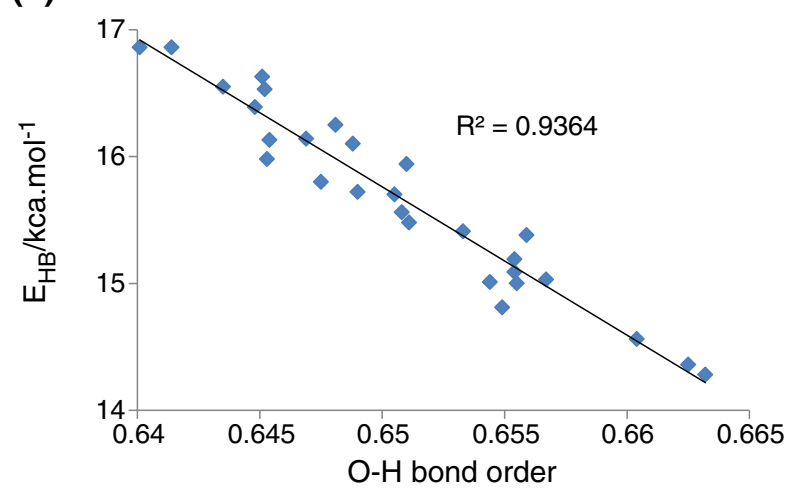

(b)



Figure 6. Linear correlations between IHB energies and (a) $\mathrm{O}-\mathrm{H}$, and (b) $\mathrm{H} \cdots \mathrm{O}$ bond orders.

\subsection{Vibrational analysis}

Vibrational spectroscopy is a powerful technique in characterization of hydrogen-bonded systems. ${ }^{53,54}$ The relations between $\mathrm{O}-\mathrm{H}$ stretching and bending vibrations with hydrogen bond strength have been known for a long time. ${ }^{53,54}$ The calculated wavenumbers of stretching and out-of-plane bending vibrational modes of $\mathrm{OH} / \mathrm{OD}$ are tabulated in table 4. The O-H/O-D stretching wavenumbers of the 4-substituted electron withdrawing and 5 -substituted electron donating groups show a blue shift and all other derivatives show a red shift, compared with that of $H B P$. On the other hand, the O-H/O-D outof-plane bending frequencies of 4-substituted electronwithdrawing and 5-substituted electron-donating groups show a red shift and all other derivatives exhibit a blue shift. These results are in good agreement with other calculated results obtained by NBO, AIM, and DFT analysis. The $E_{\mathrm{HB}}$ linear correlations with $\mathrm{OH} / \mathrm{OD}$ stretching and out-of-plane bending vibrational wavenumbers are indicated in figures $7 \mathrm{a}-7 \mathrm{~d}$, respectively. In these regression analyses, the regression coefficients $\left(\mathrm{R}^{2}\right)$ for correlations of $E_{\mathrm{HB}}$ with $\mathrm{OH} / \mathrm{OD}$ stretching and out-of-plane bending vibrational frequencies are 0.9464/0.9415 and 0.9325/0.8687,
Table 4. Selected vibrational frequencies of HBPs and their deuterated analogs $\left(\mathrm{in}^{-1}\right){ }^{\text {a }}$

\begin{tabular}{|c|c|c|c|c|}
\hline Compounds & $\nu \mathrm{OH}$ & $\nu \mathrm{OD}$ & $\gamma \mathrm{OH}^{\mathrm{b}}$ & $\gamma \mathrm{OD}^{\mathrm{b}}$ \\
\hline $3-\mathrm{NO}_{2}$ & 3260 & 2378 & 861 & 619 \\
\hline $4-\mathrm{NH}_{2}$ & 3268 & 2384 & 872 & 624 \\
\hline 3-CHO & 3271 & 2386 & 857 & 616 \\
\hline 4-MeO & 3272 & 2394 & 867 & 622 \\
\hline $4-\mathrm{OH}$ & 3272 & 2387 & 870 & 622 \\
\hline $5-\mathrm{NO}_{2}$ & 3287 & 2404 & 854 & 626 \\
\hline $3-\mathrm{CF}_{3}$ & 3289 & 2389 & 858 & 620 \\
\hline 5-CHO & 3295 & 2403 & 853 & 622 \\
\hline 3-CN & 3302 & 2408 & 850 & 609 \\
\hline 3-Cl & 3308 & 2420 & 851 & 615 \\
\hline 4-F & 3309 & 2413 & 841 & 612 \\
\hline 3-МeO & 3310 & 2414 & 849 & 611 \\
\hline 3-OH & 3310 & 2421 & 835 & 603 \\
\hline $5-\mathrm{CN}$ & 3312 & 2415 & 847 & 605 \\
\hline 4-Cl & 3320 & 2421 & 837 & 605 \\
\hline $5-\mathrm{CF}_{3}$ & 3321 & 2421 & 833 & 606 \\
\hline $3-\mathrm{CH}_{3}$ & 3322 & 2430 & 851 & 616 \\
\hline $3-\mathrm{NH}_{2}$ & 3322 & 2422 & 838 & 603 \\
\hline $4-C F_{3}$ & 3322 & 2422 & 832 & 604 \\
\hline $4-\mathrm{CH}_{3}$ & 3331 & 2436 & 836 & 604 \\
\hline $3-F$ & 3348 & 2440 & 821 & 598 \\
\hline 2HBP & 3351 & 2443 & 823 & 601 \\
\hline 4-CN & 3352 & 2443 & 818 & 598 \\
\hline 4-CHO & 3355 & 2446 & 817 & 596 \\
\hline $5-\mathrm{Cl}$ & 3356 & 2446 & 820 & 598 \\
\hline $5-\mathrm{CH}_{3}$ & 3357 & 2454 & 810 & 600 \\
\hline $4-\mathrm{NO}_{2}$ & 3361 & 2449 & 815 & 596 \\
\hline $5-\mathrm{F}$ & 3366 & 2453 & 819 & 594 \\
\hline 5-MeO & 3382 & 2472 & 799 & 587 \\
\hline $5-\mathrm{OH}$ & 3382 & 2472 & 799 & 587 \\
\hline $5-\mathrm{NH}_{2}$ & 3397 & 2475 & 795 & 582 \\
\hline
\end{tabular}

a) $v$ and $\gamma$ stand for stretching and out-of-plane bending vibrational modes, respectively.

b) In the case of coupling between $\gamma \mathrm{OH} / \gamma \mathrm{OD}$ with the phenyl $\mathrm{CH}$ deformations, averaged values calculated.

respectively. However, by excluding the 3 -substituted derivatives from the regression analysis, considerably better regression coefficients will be obtained. The calculated regression coefficients after excluding the 3-substituted derivatives for OH/OD stretching and out-of-plane bending correlations are 0.9818/0.9709 and $0.9725 / 0.9413$, respectively, which are shown in figure 7. As is apparent from figure 7, the vibrational data of 3-substituted derivatives predict lower hydrogen bond energies than those obtained by AIM calculations. These results also indicate that the steric effects maintain a high degree of contribution in reducing the $\mathrm{O} \cdots \mathrm{O}$ distance, but this reduction in bond length is not properly followed by charge redistribution. This could be considered as the main reason for deviations from Gilli's correlations. 
(a)



(c)

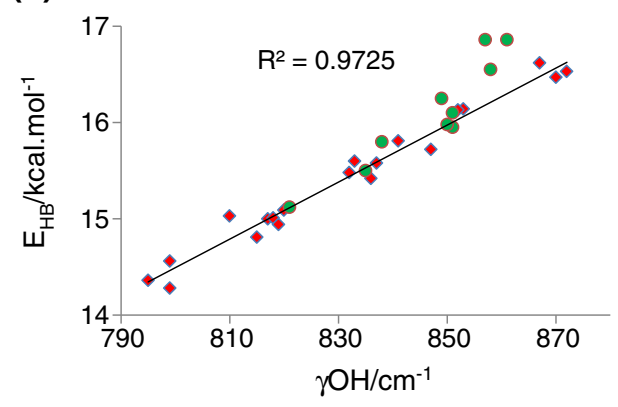

(b)

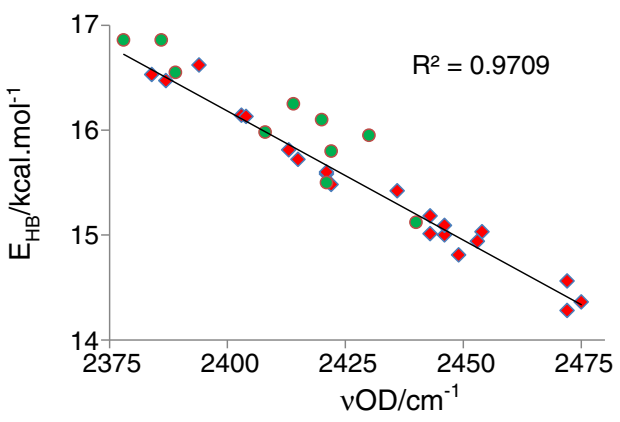

(d)

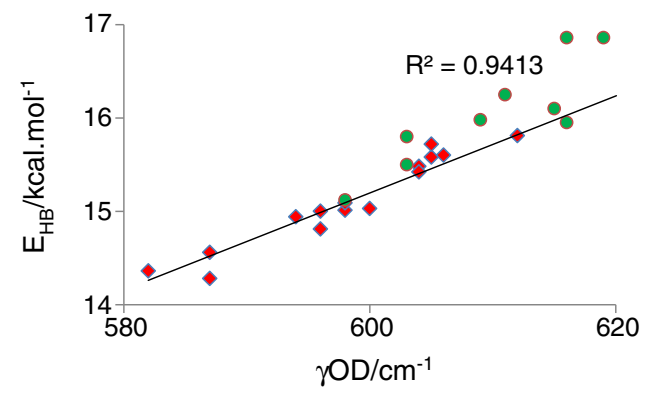

Figure 7. The $\mathrm{E}_{\mathrm{HB}}$ linear correlations with (a) $\mathrm{OH}$ stretching, (b) $\mathrm{OD}$ stretching, (c) $\mathrm{OH}$ and (d) OD out-of-plane vibrational wavenumbers for 3 -substituted derivatives, $\bullet$, and 4 - and 5 -substituted, $\diamond$.

\section{Conclusion}

The intramolecular hydrogen bonds for the $H B P$ and its 30 derivatives have been investigated using B3LYP/6$311++\mathrm{G}^{* *}$ level of theory. The results of fully optimized geometries, OH/OD stretching and out-of-plane bending vibrational modes, ${ }^{1} \mathrm{H}$ NMR, NBO, and AIM analyses show that the influence of substituents at the 3-, 4- and 5-positions on the strength of intramolecular hydrogen bonding of HBP is as follows:

3-substituted derivatives, nevertheless, to be an electron-donating or an electron-withdrawing group, increase the hydrogen bond strength mainly by steric effects. 3-FHBP, because of the small size of fluorine and acting as an electron-donating group, is an exception to this rule.

An electron-supplying group in 4-position, para with respect to $\mathrm{C} 1$, increases the $I H B$ strength by increasing the negative charge of $\mathrm{O} 15$, the proton acceptor. On the other hand, substitution of an electron-withdrawing group at this position reduces the $I H B$ strength by reducing the electron charge over $\mathrm{O} 15$.

The presence of an electron-donating group in the 5-position, para with respect to the hydroxyl group, decreases the IHB strength by inductive or mesomeric effects (increasing the negative charge over O14, the proton donor group). The presence of an electronwithdrawing group at this position increases the IHB strength by reducing the negative charge over O14.

\section{Acknowledgements}

We are grateful to the Alzahra University for their support to this research.

\section{References}

1. Weller A Z 1956 Z Elektrochem. 601144

2. Catalán J, Palomar, J and De Paz I L G 1997 J. Phys. Chem. A 1017914.

3. Klöpffer W 1977 Adv. Photochem. 10311

4. Scaiano J C 1982 Chem. Phys. Lett. 9297

5. Chou P, McMorrow D, Aartsma T J and Kasha M 1984 J. Phys. Chem. 884596

6. Catalán J, Paz J L, Valle J C D and Kasha M 1997 J. Phys. Chem. A 1985284

7. Keck J, Roessler M, Schroeder C, Stueber G J, Waiblinger F, Stein M, LeGourriérec D, Kramer H E A, Hoier H, Henkel S, Fischer P, Port H, Hirsch T, Rytz G and Hayoz P 1998 J. Phys. Chem. B 1026975

8. Padrón A J C and Aguirre G 1989 Eur. Polym. J. 2525

9. Martinez M L, Cooper W C and Chou T T 1992 Chem. Phys. Lett. 193151 
10. Suzuki T, Kitamura Sh, Khota R, Sugihara K, Fujimoto $\mathrm{N}$ and Ohta Sh 2005 Toxicol. Appl. Pharmacol. 203 9

11. Felix T, Hall B J and Brodbelt J S 1998 Anal. Chim. Acta 371195

12. Hagedorn-Leweke U and Lippold B C 1995 Pharmacol. Res. 121354

13. Schnabel W and Kiwi J 1978 In Aspects of Degradation and Stabilization of Polymers, Jellinek H H (ed.) (Amsterdam: Elsevier)

14. Weller A 1961 Prog. React. Kinet. 1189

15. Heller H J 1969 Eur. Polym. J. Suppl. 105

16. Heller H J and Blattmann H R 1972 Pure Appl. Chem. 30145

17. Heller H J and Blattmann H R 1973 Pure Appl. Chem. 36141

18. Klöpffer W 1976 J Polym. Sci. Polym. Symp. 57205

19. Maheshwari S, Chowdhury A and Sathyamurthy N 1999 J. Phys. Chem. A 1036257

20. Palomar J and De Paz J L G 2000 J. Catalan, J. Phys. Chem. A 1046453

21. Lamola A A and Sharp L J 1966 J. Phys. Chem. 702634

22. Vink P and Van Veen Th 1978 Eur. Polym. J. 14533

23. Allen N S 1986 Chem. Soc. Rev. 15373

24. Catalán J and De Paz J L G 2001 J. Phys. Chem. A 105 7315

25. Gilli G, Bellucci F, Ferretti V and Bertolasi V 1989 J. Am. Chem. Soc. 1111023

26. Hou S Y, Hetherington W M, Korenowski G M and Eisenthal K B 1979 Chem. Phys. Lett. 68282

27. Xu X, Cao Z, Zang Q and Zhang Q 2005 J. Chem. Phys. 122194305

28. Barone V and Adamo C 1997 Int. J. Quantum Chem. 61 429

29. Afzali R, Vakili M, Tayyari S F, Eshghi H and Nekoei A-R 2014 J. Spectrochim. Acta Part A 117284

30. Tayyari S F, Ghafari M, Jamialahmadi M, Chahkandi B and Wang Y A 2013 J. Mol. Struct. 104520

31. Tayyari S F, Holakoei S and Mahdizadeh S J 2013 J. Mol. Struct. 1041190

32. Tayyari S F, Laleh S, Zahedi-Tabrizi M and Vakili M 2013 J. Mol. Struct. 1038177

33. Lee C, Yang W and Parr R G 1988 Phys. Rev. B 37785

34. Gaussian 09, Revision A.02, Frisch M J, Trucks G W, Schlegel H B, Scuseria G E, Robb M A, Cheeseman J R, Scalmani G, Barone V, Mennucci B, Petersson G A, Nakatsuji H, Caricato M, Li X, Hratchian H P, Izmaylov A F, Bloino J, Zheng G, Sonnenberg J L, Hada M,
Ehara M, Toyota K, Fukuda R, Hasegawa J, Ishida M, Nakajima T, Honda Y, Kitao O, Nakai H, Vreven T, Montgomery J A Jr, Peralta J E, Ogliaro F, Bearpark M, Heyd J J, Brothers E, Kudin K N, Staroverov V N, Kobayashi R, Normand J, Raghavachari K, Rendell A, Burant J C, Iyengar S S, Tomasi J, Cossi M, Rega N, Millam N J, Klene M, Knox J E, Cross J B, Bakken V, Adamo C, Jaramillo J, Gomperts R, Stratmann R E, Yazyev O, Austin A J, Cammi R, Pomelli C, Ochterski J W, Martin R L, Morokuma K, Zakrzewski V G, Voth G A, Salvador P, Dannenberg J J, Dapprich S, Daniels A D, Farkas Ö, Foresman J B, Ortiz J V, Cioslowski J and Fox D J, Gaussian, Inc., Wallingford CT 2009

35. Biegler-König F and Schönbohm J, AIM2000 Version 2.0

36. Bader R F W, Tang Y H, Tal Y and Biegler-König F W 1982 J. Am. Chem. Soc. 104946

37. Wiberg K W 1968 Tetrahedron 241083

38. Morales C M and Weinhold F 2001 Theoretical Chemistry Institute, University of Wisconsin, Madison, WI. http://www.chem.wisc.edu/ nbo5

39. McWeeny R 1962 Phys. Rev. 1261028

40. London F 1937 J. Phys. Radium 8397

41. Bader R F W 1990 Atoms in molecules. A quantum theory (Oxford: Oxford University Press)

42. Rozas I, Alkorta I and Elguero J $2000 \mathrm{~J}$. Am. Chem. Soc. 12211154

43. Koch U and Popelier P L A 1995 J. Phys. Chem. A 99 9747

44. Wojtulewski S and Grabowski S J 2003 Chem. Phys. Lett. 378388

45. Emamian S and Tayyari S F 2013 J. Chem. Sci. 125939

46. Shainyan B A, Chipanina N N, Aksamentova T N, Oznobikhina L P, Rosentsveig G N and Rosentsveig I B 2010 Tetrahedron 668551

47. Espinosa E, Molins E and Lecomte C 1998 Chem. Phys. Lett. 285170

48. Bertolasi V, Gilli P, Ferreti V and Gilli G 1991 J. Am. Chem. Soc. 1134917

49. Saraswat K, Prasad R N, Ratnani R, Drake J E, Hursthouse M B and Light M E 2006 Inorg. Chim. Acta 3591291

50. Liebich B W and Parthé E 1974 Acta. Cryst. B 302522

51. Liebich W 1979 Acta Cryst. B 351186

52. Cox Ph J and MacManus S M 2003 Acta Cryst. C 59603

53. Novak A 1974 Struct. Bond. 18177

54. Tayyari S F, Zeegers-Huyskens T and Wood J L 1979 Spectrochim. Acta Part A 351289 